\title{
Characterization and comparison of different photopolymers for low spatial frequency recording
}

\author{
R. Fernández ${ }^{1}$, S. Gallego ${ }^{1,2, *}$, J. Francés ${ }^{1,2}$, I. Pascual ${ }^{1,3}$, A. Beléndez ${ }^{1,2}$
}

${ }^{1}$ Instituto Universitario de Física Aplicada a las Ciencias y las Tecnologías, Universidad de Alicante. Apartado 99, 03080 Alicante, Spain

2 Departamento de Física, Ingeniería de Sistemas y Teoría de la Señal. Universidad de Alicante. Apartado 99. E03080 Alicante, Spain

3 Departamento de Óptica, Farmacología y Anatomía. Universidad de Alicante. Apartado 99. E03080 Alicante, Spain

* E-Mail: sergi.gallego@ua.es; Tel./Fax: +34-96-5903400.

\begin{abstract}
Free-radical photopolymer materials can be fabricated using a wide range of monomers, binders, dyes, etc. It was shown that in some photopolymers the surface and the internal diffusion for acrylamide materials are very different and also it was demonstrated the viability of acrylamide materials to achieve $2 \pi$ phase depth for low spatial diffractive optical elements. Building on the work developed previously, in this paper, a characterization and a comparison is carried out for three different photopolymers: crosslinked acrylamide based photopolymers, a biophotopol and an H-PDLC material. We have measured the motion of the components inside the material and through the surface using a new index matching component and through the surface. We have studied the introduction of different crosslinkers in order to increase the refractive index modulation and to reduce the thickness required to achieve a phase depth higher than $2 \pi$ in the diffraction optical elements.
\end{abstract}

\section{Introduction}

The correct fitting of the monomer diffusion was the aim of the several works carried out by different research groups, specially, for acrylamide based photopolymers. Recently it was proposed the using of index matching methods to decoupling the 
surface and internal changes. As discussed in a previous papers [1, 2], the method proposed can be applied when new chemical compounds are introduced, even for different photopolymer families such as Biophotopolymers or HPDLC ones. The previous studies can be widely applied to analyze the viability of different photopolymers to record diffractive optical elements (DOEs) like lenses, axicons or blazed gratings [3-7]. Moreover the velocity of surface changes and the diffusion of the monomer inside the layer can be fitted too using the method described in [1,2]. The many applications of such free-radical photopolymer materials [8-12] make the analysis of the diffusion process very interesting.

In the commented manuscript, [1], the influence of index matching to measure the rate of diffusion of monomer in an acrylamide material, AA, was developed. The results indicated that this type of material is a very appealing candidate to record DOEs when the thickness is higher than $105 \mu \mathrm{m}$. Nevertheless large values of thickness occasionally produce an increase in the scattering and instabilities in the final hologram or diffractive optical elements stored [13]. Therefore on the first place, in this paper, we report the experiments for AA photopolymer, we show as the phase modulation can be increased avoiding layers thicker than $100 \mu \mathrm{m}$ for AA materials. AA based photopolymer is one of the most studied in the literature [4,5,14-16]. The main problem of this type of photopolymers is the important toxicity of the main monomer, AA. Some efforts have been made to substitute this component in the chemical formulations so as to design highly compatible environmental photopolymers [17-20]: one of the greenest photopolymers is called Biophotopol [19], BIO. A photopolymer based in this material will be the second material analyzed in this work. In particular we study some different chemical variations of Biophotopol incorporating different crosslinker monomers in order to study the optimum thickness to fabricate $2 \pi$ phase depth elements for each chemical variation of BIO photopolymers. The Biophotopol is a material with non-toxic nature and high environmental compatibility, wide dynamic range and high holographic sensitivity, together with its self-processing nature and low cost of production; make it a potentially excellent candidate for applications such as holographic sensors [21], diffractive optics or data storage [22].

On the last place we have evaluated a photopolymer with dispersed liquid crystal molecules, H-PDLC [23-27], for recording DOEs in the low spatial frequency range. Nowadays new components have been included in the standard formulation of classical photopolymer systems to arise unexpected properties, some examples of these components are nano-particles or dispersed liquid crystal molecules (LC), by combining polymers and dispersed liquid crystals a new spectrum of interesting applications was opened. The opportunity to design new switchable or tunable holographic displays due to phase separation between photopolymer and LC has attracted great attention. For example, the ability to control the diffraction efficiency of holographic optical elements 
by applying an electric field leads to the possibility of using holographic optical elements in dynamic applications for agile beam steering, nonlinear optics and optical switching devices [23-25]. This family of polymers is known as H-PDLC. In the chemical formulation multifunctional monomers are used in order to induce a phase separation process (PIPS) in which the liquid crystal molecules diffuse to dark zones in the diffraction grating where, once the corresponding element has been recorded, they can be oriented by means of an electric field. The orientation of the liquid crystal produces a refractive index variation which changes the diffraction efficiency. Therefore, the grating develops a dynamic behavior that may be modified by electronic means. In this manner, it is possible to make dynamic devices such as tunable-focus lenses, sensors, phase modulators or prism gratings. H-PDLCs are characterized by high values of refractive index modulation that provide diffraction efficiencies close to $100 \%$ for an optical thickness around $10 \mu \mathrm{m}$, and the main drawback is the high value of scattering. The novelty presented here is the application of H-PDLCs to fabricate low spatial frequency EOD. To obtain this goal, on the last part of the paper we characterize the observable monomer diffusion, refractive index modulation and the optimum thickness required to fabricate $2 \pi$ phase depth DOE in a standard H-PDLC photopolymer [27]. To summarize, along this work, we report the complete characterization to produce optimized DOE in three different photopolymer families.

Let us introduce Fig. 1, diffraction efficiencies, DEs, of the main diffracted orders for phase thin gratings as a function of the phase depth, thus enabling readers to evaluate directly the phase modulation achieved just comparing the experimental results to this figure.

\section{Material and preparation}

As we have said in a previous paper the standard photopolymer is composed of $\mathrm{AA}$ as polymerizable monomer, triethanolamine (TEA) as coinitiator and plasticizer, yellowish eosin (YE) as dye, PVA as binder and a small proportion of water as additional plasticizer. It may also contain N,N'-methylene-bis-acrylamide (BMA) as crosslinking monomer. AA and BMA are toxic monomers, the former more than the latter. YE also introduces problems due to the four $\mathrm{Br}$ atoms in its molecule, but it is clearly the less toxic component. In this sense in the chemical formulation analyzed in this work we keep YE as a dye, to obtain a better comparison of the monomer importance.

For monomer substitution it is necessary to use another vinyl monomer that is less toxic than AA. We used sodium acrylate, $\mathrm{NaAO}$, prepared in situ by means of a one-pot reaction with acrylic acid and sodium hydroxide in the prepolymer solution used to prepare the layers. The toxicity of sodium acrylate is lower than that of AA. We replaced AA by $\mathrm{NaAO}$ in the photopolymers BIO.

BMA, a known also toxic, but clearly less than AA, is the crosslinker usually used in a standard AA-based photopolymer. We used N,N'-(1,2-dihydroxyethylene) 
bisacrylamide (DHEBA) in biophotopol as an alternative to BMA. DHEBA has occasionally been used in hydrophilic photopolymers due to its good solubility in water. This molecule is suitable for the new photopolymer because its two hydroxyl groups are compatible with the structure of sodium polyacrylate generated in the photopolymerization. In this manner, hydrogen bonds may be formed with the PVA binder and TEA and water plasticizers. Although there are no studies in the literature suggesting that this substance is toxic, future research may show it has a certain level of toxicity; however, it is less toxic than BMA.

Biophotopol has also a hydrophilic binder as the AA-based standard photopolymer and this implies that during its production the main solvent used is water. Biophotopol does not use any additional co-solvent. Any products and devices made with this photopolymer can also be eliminated, once their useful life is over, by dissolving in water. Therefore, this material has an advantage over hydrophobic photopolymers because it avoids the use of petroleum-based solvents, which are toxic and flammable.

Analyzed solutions for AA and Bio, whose compositions can be seen in Table 1, are deposited, using the force of gravity, on a glass substrate $(25 \mathrm{~cm} \times 20 \mathrm{~cm})$, and left in the dark $\left(\mathrm{RH}=40-45 \%, \mathrm{~T}=20-23^{\circ} \mathrm{C}\right)$. When part of the water has evaporated (after about 36 hours), the layer has enough mechanical resistance and can be cut without deforming. The final "solid" film has a physical thickness around $90 \pm 5 \mu \mathrm{m}$. This final thickness can be modified changing the quantity of the syrup deposited on the glass with the same method of preparation thicknesses between 30 and $250 \mu \mathrm{m}$ had been successfully fabricated [26].

Table 1. Composition of photopolymer AA and BIO, liquid solutions.

\begin{tabular}{|c|c|c|c|c|c|}
\hline $\begin{array}{c}\text { Composition } \\
\text { name }\end{array}$ & AA1 & AA2 & BIO1 & BIO2 & BIO3 \\
\hline $\begin{array}{c}\text { NaAO } \\
(\mathbf{g})\end{array}$ & ----- & ----- & 1 & 1.5 & 1.5 \\
\hline $\begin{array}{c}\text { TEA } \\
(\mathbf{m l})\end{array}$ & 2.0 & 2.0 & 2 & 3.0 & 3.0 \\
\hline $\begin{array}{c}\text { PVA (ml) } \\
(\mathbf{8} \% \mathbf{w} / \mathbf{v})\end{array}$ & 25 & 25 & 30 & 25 & 25 \\
\hline $\begin{array}{c}\text { YE (0.8\% } \\
\mathbf{w} / \mathbf{v}) \\
(\mathbf{m l})\end{array}$ & 0.6 & 0.6 & 0.84 & 0.6 & 0.6 \\
\hline DHEBA (g) & ------ & ------ & ----- & 0.18 & ----- \\
\hline $\begin{array}{c}\text { BMA } \\
(\mathbf{g})\end{array}$ & ------ & 0.2 & ------ & ------ & 0.18 \\
\hline $\begin{array}{c}\text { AA } \\
(\mathbf{g})\end{array}$ & 0.96 & 0.84 & ----- & ------ & ------ \\
\hline $\begin{array}{c}\text { Thickness } \\
\mathbf{\pm} \mathbf{( \mu m )}\end{array}$ & 90 & 90 & 90 & 90 & 90 \\
\hline
\end{tabular}

To fabricate H-PDLC photopolymer, the monomer used is dipentaerythritol penta/hexaacrylate (DPHPA) with a refractive index $n=1.490$. We use the nematic liquid crystal, licristal ${ }^{\circledR}$ BL036 from Merck. It is a mixture of 4-cyanobiphenyls with alkyl chains of different lengths. It has an ordinary refractive index $\mathrm{n}_{0}=1.5270$, and a difference between extraordinary and ordinary index $\Delta \mathrm{n}=0.2670$ [26]. There is a difference of 0.037 between the ordinary refractive index of the liquid crystal and that of the 
monomer. The liquid crystal concentration was set at $28 \mathrm{wt} \%$ as the starting point for component optimization and remained practically unchanged during this process.

$\mathrm{N}$-vinyl-2-pyrrolidone (NVP) was used as crosslinker, N-phenyl glicine (NPG) as radical generator and octanoic acid (OA) as cosolvent [27]. We used ethyl eosin (YEt) as dye.

The H-PDLC prepolymer solution is made by mixing the components under red light where the material is not sensitive. The solution is sonicated in an ultrasonic bath, deposited between two conductive ITO glass plates $1 \mathrm{~mm}$ thick and separated using two types of glass microspheres. The microspheres were provided by Whitehouse scientific with a thickness between $20-30 \mu \mathrm{m}$. The device is exposed to a laser beam $(\lambda=532 \mathrm{~nm})$ in a holographic set-up in order to record a diffraction grating in the photopolymer layer. A photopolymerization reaction takes place in the bright zones of the diffraction grating and a highly reticulated polymer network is generated. The liquid crystal molecules diffuse to the unexposed region where they remain as nano-droplets. In this work we used chemical compositions represented in Table 2.

Table 2. Composition of photopolymer H-PDLC in wt $\%$

\begin{tabular}{|c|c|c|c|c|c|c|}
\hline photopolymer & DPHPA & BL036 & YEt & NPG & NVP & OA \\
\hline H-PDLC & 48.4 & 29.2 & 0.1 & 1.5 & 16.4 & 4.4 \\
\hline
\end{tabular}

\section{Results and discussion}

In this section we compare the behaviour of the different materials fabricated in low spatial frequency recording regime. In particular, for a spatial period of $168 \mu \mathrm{m}$ we analyse different photopolymer families. In this Paper in order to increase the phase modulation we introduce crosslinker monomers to modify the material properties. For each chemical composition we analyze which value of the material thickness is enough to achieve a phase depth of $2 \pi$. Finally we estimate the "apparent" diffusion in uncovered samples and the internal diffusion in the index matched ones.

\subsection{AA photopolymer}

We have commented the possibility of increasing the phase modulation using thicker layers as it has been shown in a previous paper [1]. Other alternative is introducing additional compound in the chemical composition of the material such as crosslinker monomers or nanoparticles. It is complicate for very low spatial frequency recording to obtain the right level of phase separation between the polymer and the nanoparticles, due to the large values of the spatial period. For AA photopolymers the crosslinker most widely used is BMA, thus we use this compound to increase the phase depth as depicted in Fig. 2, which shows the DE for the main diffracted orders as a function of the exposure. Comparing this Fig. 2 to Fig.1 it can be seen that the phase depth of $2 \pi$ is achieved after $100 \mathrm{~s}$ of exposure time. Then, after $200 \mathrm{~s}$ of recording the phase depth becomes around 1.4 times $2 \pi$ for this sample with a thickness of $95 \mu \mathrm{m}$. Therefore for this chemical composition, AA2, the phase shift of $2 \pi$ between exposed 
and non-exposed zones could be obtained using a thickness of $68 \mu \mathrm{m}$. This value is much thinner than the required for composition AA1, which was $105 \mu \mathrm{m}$ as is presented in ref. [1]. Thus the presence of crosslinker BMA can improve drastically the material properties at very low spatial frequency recording range.

Let us now study the influence of the index matched samples for composition AA2 and measure the monomer diffusion for this chemical compositon. To achieve this goal we have exposed this layer during 100s and after that we have studied the evolution of the diffracted orders after recording. The results are presented in Fig. 3 and as it can be detected are very similar than the ones obtained in ref. 1 for chemical compositon AA1. Due the low quantity of crosslinker in the photopolymers syrop the refractive index of the "dry" layer does not change significatly and we can assume that the slow variation of DEs after recording is due only to the internal diffusion. To calculate the value of the monomer diffusion we follow the method proposed in a previous papers $[1,28]$ then we wait several minutes after recording. From the fitting depicted in Fig. 4 we obtain the monomer diffusion in this case is around $2 \cdot 10^{-10} \mathrm{~cm}^{2} / \mathrm{s}$. This is very similar to the obtained for compositon AA1 in ref. [1]. This result makes sense due to the small differences in the molar concentration between chemical compositions AA1 and AA2 and the higher size of BMA when is compared to AA molecules.

\subsection{BIO photopolymers}

Taking into account the demand of high environmental products, some new "greener" photopolymers have been designed [19]. In this sense Biophotopol is a good solution and it is the only photopolymer completely environmentally compatible. In this section we have compared the three proposed chemical compositions: BIO1, BOI2 and BIO3. The evolution of the DEs for the first composition, where no crosslinker is used, without index matching, is plotted in Fig. 5. As can be seen the formation of the phase gratings is much slower than the measured in AA photopolymers. Furthermore the phase depth achieved after $700 \mathrm{~s}$ of recording is around $\pi$ for a sample with thickness of $90 \mu \mathrm{m}$. Therefore, for composition BIO1 the thickness should be increased double to be capable to record phase elements with phase depth close to $2 \pi$. To increase the phase depth we propose the incorporation of different crosslinker monomers to the composition BIO1. The first one it is DHEBA and is characterized by its high environmental compatibility and the second one is BMA the most commonly used with AA photopolymers. The results are depicted in Fig.6a and 6.b respectively. As it can be deduced both compositions improve the results obtained by BIO1. In particular, we see that $\mathrm{BIO} 3$ provided high values of phase depth, close to the desired value of $2 \pi$. It is important to note that DHEBA has an additional and interesting property: this compound is able to dissolve the $\mathrm{NaAO}$ increasing the utility life of the samples ten times, preventing the monomer crystallization.

Due to the similarities between the binder in AA and BIO photopolymers, both present important relief structures formed during recording. This fact avoids the separated analysis of the refractive index distribution generated by polymerization. In 
order to analyse the effects of the index matching in this family of photopolymers we present the results provided by composition $\mathrm{BIO} 2$, but in general the results are very similar for the three bio-compositions analysed. The results are presented in Fig. 7. Avoiding the relief effects the maximum of the DE for the first order is achieved faster, as with the results obtained in ref. [1] for AA photopolymers. As can be seen for BIO2 with $90 \mu \mathrm{m}$ the maximum phase depth is around $1.4 \pi$. Therefore assuming a linear behaviour with thickness a sample $128 \mu \mathrm{m}$ thick will be required to achieve a phase depth of $2 \pi$.

In order to measure the "apparent" monomer diffusion we have analysed the postevolution of DEs after 100s of recording for compositions BIO1 and after 50 seconds for composition BIO 3, Fig 8.a and 8.b respectively. It can be seen in both figures how after recording the DE of the 0 order it continues diminishing and the DE of first order keeps growing due to the swelling in the illuminated zones. As a first approximation the post-evolution looks very similar in both cases. The fitted values for the apparent diffusion confirm this hypothesis. The results for BIO3 are represented in Fig. 9, and once again in this figure it is shown the good agreement between the model and the experimental data. It is important to remark that for BIO materials the "apparent" diffusion, for no index matched samples, is clearly slower than for AA photopolymers: it was around $2 \cdot 10^{-8} \mathrm{~cm}^{2} / \mathrm{s}$ for AA based ones and it is around $4 \cdot 10^{-9} \mathrm{~cm}^{2} / \mathrm{s}$ for BIO based ones. These results agree to the ones presented in [29-30].

Let us discuss about the index matching method for BIO materials to calculate the internal diffusion, never measured before in BIO materials. In principle the requirements for a good index matching liquid are clear in the literature. The liquid should not change the chemical properties of the holographic recording material, furthermore it should present no solubility in the material and on last place, but not less important, the refractive index of the liquid should be extremely close to the average recording material refractive index. In the case of AA photopolymers our choice was almost perfect: both refractive index match to the third decimal number (it was 1.477). For BIO samples the photopolymer present lower value of refractive index before exposure in particular $\mathrm{n}=1.471$, therefore to obtain an optimum index matching we use a non-water soluble liquid with $n=1.4696$. The results during 100 s of exposure time and the subsequent post evolution are presented in Fig. 10.a and the fitted values to obtain the diffusion time constant in Fig. 10.b. From the fitting depicted in Fig. 10.b we obtain that the monomer diffusion in this case is around $10^{-10} \mathrm{~cm}^{2} / \mathrm{s}$. The results indicate that the internal monomer diffusion is a bit slower, twice, in BIO material when compared to AA, as it was measured in non-covered samples for "apparent" diffusion.

\subsection{H-PDLC photopolymers}

H-PDLC materials are one of the more widely used in holography and also have very appealing properties for photonics applications. In order to analyze the usefulness for low spatial frequency recording and characterize the apparent monomer diffusion we have followed the same steps applied for AA and BIO materials. One of the main 
drawbacks dealing with H-PDLC photopolymers is the high shrinkage presented for some compositions, in order to avoid this phenomenon some techniques are proposed [31]. This family of polymers is always enclosed between two ITO glasses, and the properties of the hologram or diffracted elements can be switched by the application of an electric field. This special experimental geometry makes impossible to use the index matching method applied for AA and BIO materials. Therefore for this kind of materials only the "apparent" diffusion can be fitted. The results for 600 s of recording of a grating with spatial period of $168 \mu \mathrm{m}$ are presented in Fig. 11.a and as it can be seen the phase depth of $2 \pi$ can be achieved using a sample of $30 \mu \mathrm{m}$. We expected this result taking into account previous studies carried out with similar photopolymers to store holograms. And other additional question is the possibility of tenability of DOEs fabricated with this photopolymer. The effects of phase separations, called PIP, should be more complicated at very low spatial frequency range. In our materials we have not observed any changes when a voltage of $100 \mathrm{~V}$ is applied. In this sense it is important to notice that to obtain a good switching behavior at low thickness of samples, around 10 $\mu \mathrm{m}$, is more appropriated, then high values of electric field inside the material can be produced easier. The results obtained, using this composition, are presented in Figure 11. In Fig.11.b the DEs of the two main orders are depicted for an exposure of 50s and the post evolution. These data can be used to obtain the "apparent" monomer diffusion following the steps presented in ref. [1]. The fitting is presented in Fig. 11.c with good agreement between the experiments and the straightforward model proposed. The value obtained for these types of materials is $10^{-8} \mathrm{~cm}^{2} / \mathrm{s}$. H-PDLC are liquid at room temperature, $25^{\circ} \mathrm{C}$, and the value of the "apparent" diffusion value is similar to that of the AA photopolymers without index matching, even though these ones are "solid" at room temperature. This result suggests the possibility of two diffusion processes in PVA materials, one through the surface, faster and other internal, slower, due to the difficulties for molecules for travelling inside.

To sum it up, we have summarized the results fitted for "apparent" and internal monomer diffusion in Table 3 and the minimum thickness to achieve phase elements with phase depth of $2 \pi$ in Table 4 . From the optical point of view the more suitable materials for low spatial frequency recording are AA and H-PDLC materials. The main drawback of H-PDLC is the impossibility to minimize the shrinkage effects by means the standard index matching technique. On the other hand the attractive possibility of obtaining switchable phase elements makes a deeper evaluation relevant for these materials. On the last place, despite the BIO materials can be used for this application providing high environmental compatibility, their optical properties are a bit less optimal when compared to the rest of the studied photopolymer families.

\begin{tabular}{|l|l|l|l|}
\hline Composition name & AA & BIO & H-PDLC \\
\hline
\end{tabular}




\begin{tabular}{|c|c|c|c|}
\hline $\begin{array}{c}\text { "apparent" diffusion } \\
\left(\mathrm{cm}^{2} / \mathrm{s}\right)\end{array}$ & $2 \cdot 10^{-8}$ & $2 \cdot 10^{-9}$ & $1 \cdot 10^{-8}$ \\
\hline $\begin{array}{c}\text { Internal diffusion } \\
\left(\mathrm{cm}^{2} / \mathrm{s}\right)\end{array}$ & $2 \cdot 10^{-10}$ & $10^{-10}$ & ----- \\
\hline
\end{tabular}

Table 3. Fitted values for monomer diffusion with and without index matching.

Table 4. Minimum thickness to achieve a phase depth of $2 \pi$ at low spatial frequency range.

\begin{tabular}{|c|c|c|c|c|c|c|}
\hline & AA1 & AA2 & BIO1 & BIO2 & BIO3 & $\begin{array}{c}\text { H- } \\
\text { PDLC }\end{array}$ \\
\hline $\begin{array}{c}\text { Thickness } \\
\text { required } \\
(\boldsymbol{\mu m})\end{array}$ & 105 & 95 & 200 & 130 & 105 & 30 \\
\hline
\end{tabular}

\section{Conclusions}

Along this paper we have applied the method presented in ref. [1] and in [20] to different families of photopolymers to analyze the requirements to achieve $2 \pi$ phase for each chemical composition and to obtain the "apparent" and "internal" values of monomer diffusion. We have compared the effects of different crosslinker monomers in order to increase the phase difference between exposed and non-exposed zones for AA and BIO photopolymers. For BIO materials we have shown that BMA provide higher values of refractive index variations than DHEBA, on the other hand DHEBA increase the stability of the solutions and prevents the NaOA precipitation. The effects of the index matching for AA and Bio photopolymers have been also analyzed. On the last place we have demonstrated that H-PDLC materials are also good candidates for low spatial frequency elements fabrication.

\section{Acknowledgments}


The work was supported by the "Ministerio de Economía y Competitividad" of Spain under projects FIS2011-29803-C02-01 and FIS2011-29803-C02-02 and by the "Generalitat Valenciana" of Spain under projects PROMETEO/2011/021 and ISIC/2012/013.

\section{References}

1. R. Fernández, S. Gallego, A. Márquez, J. Francés F.J. Martínez, I. Pascual, A. Beléndez "Influence of the index matching on AA/PVA photopolymers for low spatial frequency recording” Applied Optics, 2013. (Submitted).

2. C. E. Close, M. R. Gleeson and J. T. Sheridan "Monomer Diffusion Rates in Photopolymer Material: Part I: Low Spatial Frequency Holographic Gratings" JOSA B; 28, 658-666.( 2011).

3. J. Neumann, K. S. Wieking, D. Kip, "Direct laser writing of surface reliefs in dry, self-developing photopolymer films,". Appl. Opt. 38, 5418-5421 (1999).

4. X. T. Li, A. Natansohn, P. Rochon, "Photoinduced liquid crystal alignment based on a surface relief grating in an assembled cell", Appl. Phys. Lett.; 74, 3791-3793 (1999).

5. A. Márquez, S. Gallego, M. Ortuño, E. Fernández, M. Alvarez, A. Beléndez, I. Pascual, "Generation of diffractive optical elements onto a photopolymer using a liquid crystal display". Proc. SPIE 2010, 7717, art. 77170.

6. S. Gallego, A. Márquez, M. Ortuño, J. Francés, I. Pascual and A. Beléndez, "Relief diffracted elements recorded on absorbent photopolymers," Opt. Express 20, 11218-11231 (2012).

7. H. Wang and F. Gan, "Phase-Shifting Apodizers for Increasing Focal Depth," Appl. Opt.; 41, 5263-5266, (2002).

8. E. Hata, K. Mitsube, K. Momose and Y. Tomita "Holographic nanoparticlepolymer composites based on step-growth thiol-ene photopolymerization," Opt. Mater. Express; 1, 207-222, (2011) .

9. M. S. Li, S. T. Wu, A. Y-G Fuh "Sensor for monitoring the vibration of a laser beam based on holographic polymer dispersed liquid crystal films," Opt. Express, 18, 26300-26306 (2010).

10. M. R. Gleeson, J. T. Sheridan, F. Bruder, T. Rölle, H. Berneth, M. Weiser, and T. Fäcke, "Comparison of a new self developing photopolymer with AA/PVA based photopolymer utilizing the NPDD model," Opt. Express 19, 26325-26342 (2011).

11. D. Cody, A. Casey, I. Naydenova, and E. Mihaylova, "A Comparative Cytotoxic Evaluation of Acrylamide and Diacetone Acrylamide to Investigate Their Suitability for Holographic Photopolymer Formulations," International Journal of Polymer Science, vol. 2013, Article ID 564319, 6 pages, 2013. 
12. E. Andrzejewska "Photopolymerization kinetics of multifunctional monomers" Progress in Polymer Science, 26, 605-665 (2001).

13. J. H. Lee, R.K. Prud'homme, and I. H. Aksay "Cure depth in photopolymerization: Experiments and theory," J. Mater. Res., 16, 3536-3544 (2001).

14. M. Květoň1, A. Havránek, P. Fiala and I. Richter, "The Experimental Study of Acrylamide Based Photopolymer Recording Materials for Applications in Optical Holography," Macromolecular Symposia 268, 115-119 (2008).

15. J. Zhu, G. Wang, Y. Hao, B. Xie, and A. Y. S. Cheng, "Highly sensitive and spatially resolved polyvinyl alcohol/acrylamide photopolymer for real-time holographic applications," Opt. Express 18, 18106-18112 (2010).

16. T. Babeva, I. Naydenova, S. Martin, V. Toal, "Method for characterization of diffusion properties of photopolymerisable systems," Opt. Exp. 16, 12, 8487-8497 (2008).

17. D. Cody, I Naydenova, and E. Mihaylova, "Effect of glycerol on a diacetone acrylamide-based holographic photopolymer material," Appl. Opt. 52, 489-494 (2013).

18. S. Gallego, A. Márquez, M. Ortuño, S. Marini and J. Francés, "High environmental compatibility photopolymers compared to PVA/AA based materials at zero spatial frequency limit," Opt. Materials 33, 531-537 (2010).

19. M. Ortuño, E. Fernández, S. Gallego, A. Beléndez, I. Pascual, "New photopolymer holographic material with sustainable design", Optics Express, 15, 12425-12434, (2007).

20. D. Cody, I. Naydenova, and E. Mihaylova, "New non-toxic holographic photopolymer," J. Opt. 14, 015601 (2012).

21. E. Leite, I. Naydenova, S. Mintova, L. Leclercq, and V. Toal, "Photopolymerizable nanocomposites for holographic recording and sensor application," Appl. Opt. 49, 3652-3660 (2010).

22. M. Ortuño, S. Gallego, A. Márquez, C. Neipp, I. Pascual, A. Beléndez, "Biophotopol: a sustainable photopolymer for holographic data storage applications", Materials 5, 772-783 (2012).

23. M. S. Li, A. Y. Fuh, J. Liu, and S. Wu, "Bichromatic optical switch of diffractive light from a BCT photonic crystal based on an azo component-doped HPDLC," Opt. Express 20, 25545-25553 (2012).

24. V. K. S. Hsiao, Ch. Lu, G. S. He, M. Pan, A. N. Cartwright, P. N. Prasad, R. Jakubiak, R. A. Vaia, T. J. Bunning "High contrast switching of distributedfeedback lasing in dye-doped H-PDLC transmission grating structures," Opt. Express. 13, 3787-3794 (2005).

25. M. Infusino, A. D. Luca, V. Barna, R. Caputo, C. Umeton "Periodic and aperiodic liquid crystal-polymer composite structures realized via spatial light modulator direct holography," Opt. Express. 20, 23138-23143 (2012). 
26 M. Ortuño, S. Gallego, C. García, C. Neipp, I. Pascual, A. Beléndez, "Holographic characteristics of an acrylamide/bisacrylamide photopolymer layers 40-1000 $\mu \mathrm{m}$ thick", Physica Scripta T118, 66-68 (2005).

27. M. Ortuño, M. Riquelme, S. Gallego, A. Márquez, I. Pascual, and A. Beléndez, "Overmodulation Control in the Optimization of a H-PDLC Device with Ethyl Eosin as Dye," International Journal of Polymer Science V. Article ID 357963, 8 pages (2013).

28. S. Gallego, A. Márquez, M. Ortuño, A. Francés, I. Pascual and A. Beléndez, "Diffractive and interferometric methods to characterize photopolymers with liquid crystal molecules as holographic recording material". Journal Of The European Optical Society - Rapid Publications, 7. doi:10.2971/jeos.2012.12024 (2012).

29. S. Gallego, A. Márquez, M. Ortuño, J. Francés, S. Marini, I. Pascual and A. Beléndez, "Surface relief model for without coverplating photopolymers", Optics Express 9, 10896-10906 (2011).

30. S. Gallego, A. Márquez, M. Ortuño, S. Marini, I. Pascual and A. Beléndez "Monomer diffusion in sustainable photopolymers for diffractive optics applications", Optical Materials 33, 1626-1629 (2011).

31. Y. J. Liu, X.W. Sun, "Holographic polymer-dispersed liquid crystals: materials, formation, and applications," Adv. Optoelectron. 1-52 (2008).

\section{Figure captions}

Fig. 1. Diffraction efficiency for the first four orders for a sinusoidal grating as a function of the phase depth

Fig. 2.- Experimental diffraction efficiencies for chemical composition AA2, during 200s recording of a grating with spatial period $168 \mu \mathrm{m}$, a sample with $95 \mu \mathrm{m}$ of thickness a) without coverplating

Fig. 3.- DEs of the four main orders as a function of time for a 100s of exposure and then post-evolution for coverplated layer with BMA, AA2. 
Fig. 4.- Experimental values fitted using method described in ref. [1] after the 100s of recording for composition AA2 index matched and coverplated.

Fig. 5.- Experimental diffraction efficiencies for chemical composition BIO1, during 600 s recording of a grating with spatial period $168 \mu \mathrm{m}$, a sample with $90 \mu \mathrm{m}$ of thickness a) without coverplating

Fig. 6.- Experimental diffraction efficiencies during recording of a grating with spatial period $168 \mu \mathrm{m}$ with samples with thickness of $90 \mu \mathrm{m}$ a) composition BIO2, b) Composition BIO3.

Fig. 7.- Experimental diffraction efficiencies for chemical composition $\mathrm{BIO} 2$, during 500s index matched.

Fig. 8.- Experimental diffraction efficiencies during recording and the post evolution for no index matched samples. a) For BIO1 100s of recording. b) For BIO3 after 50 s of recording.

Fig. 9.- Experimental values fitted using method described in ref. [1] after 50s of recording for composition $\mathrm{BIO} 3$ without index matching.

Fig. 10.- Index matched BIO3 sample, $90 \mu \mathrm{m}$ thick, 100s of exposure a) Experimental diffraction efficiencies during recording and the post evolution. b) Experimental values fitted using method described in ref. [1].

Fig. 11.- Experimental diffraction efficiencies for chemical H-PDLC composition with thickness of $30 \mu \mathrm{m}$. a) Continuous exposure. b) during 50s of exposure and the post-evolution. c) Fitting to obtain the "apparent" monomer diffusion. 
FIGURE 1

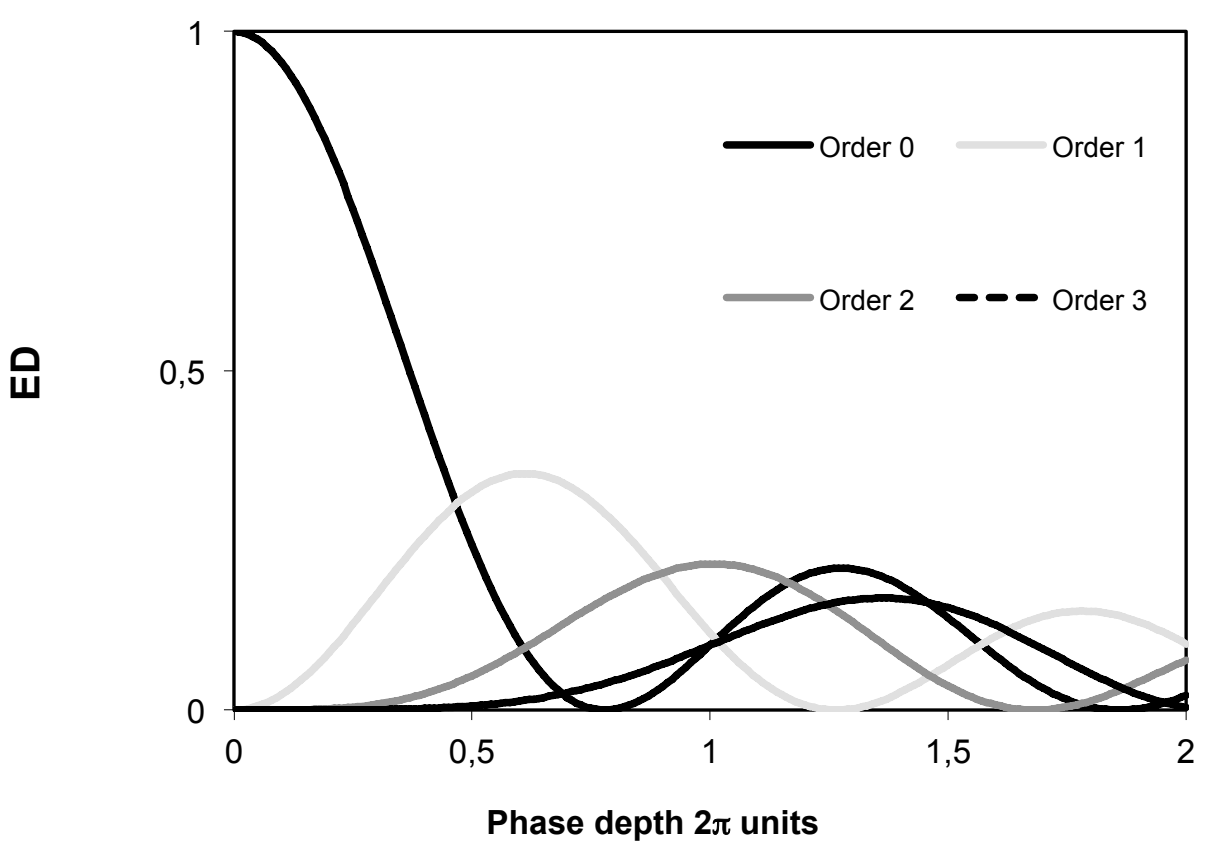


FIGURE 2

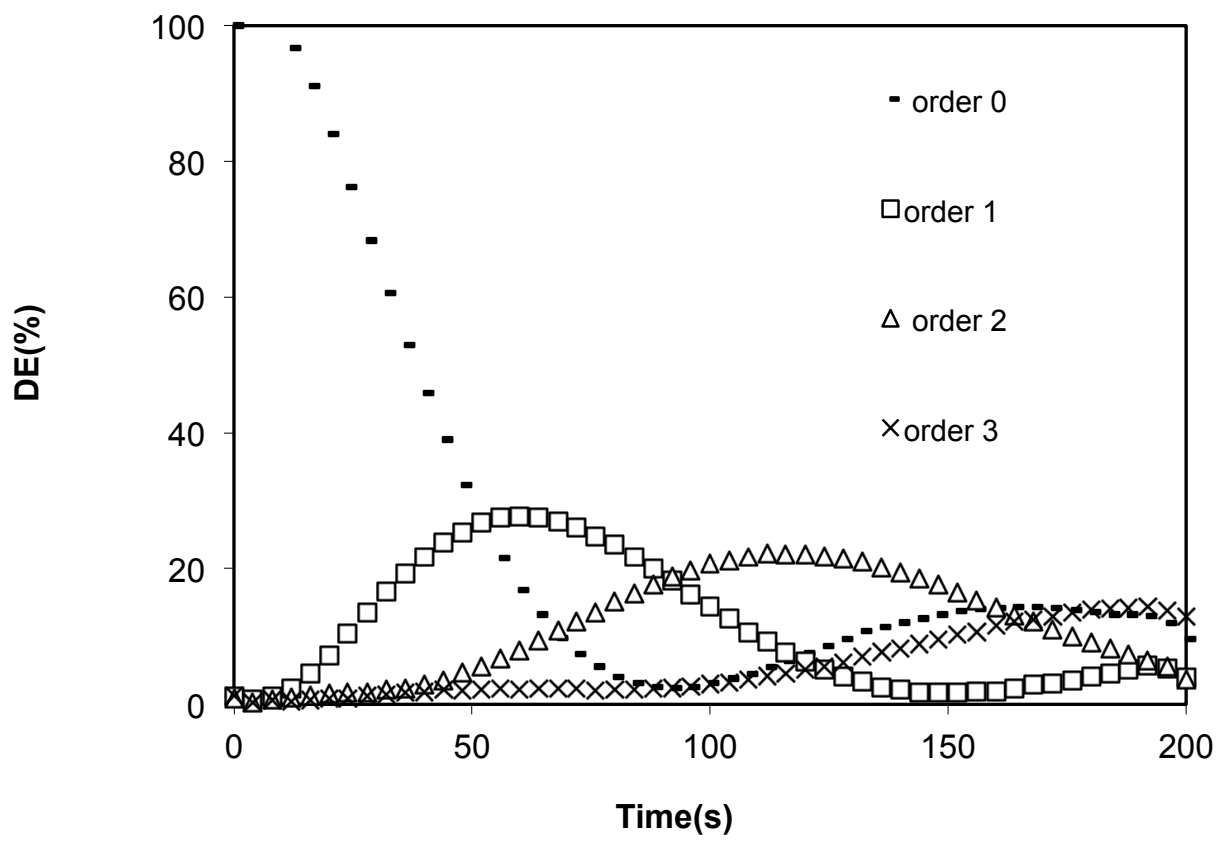


FIGURE 3

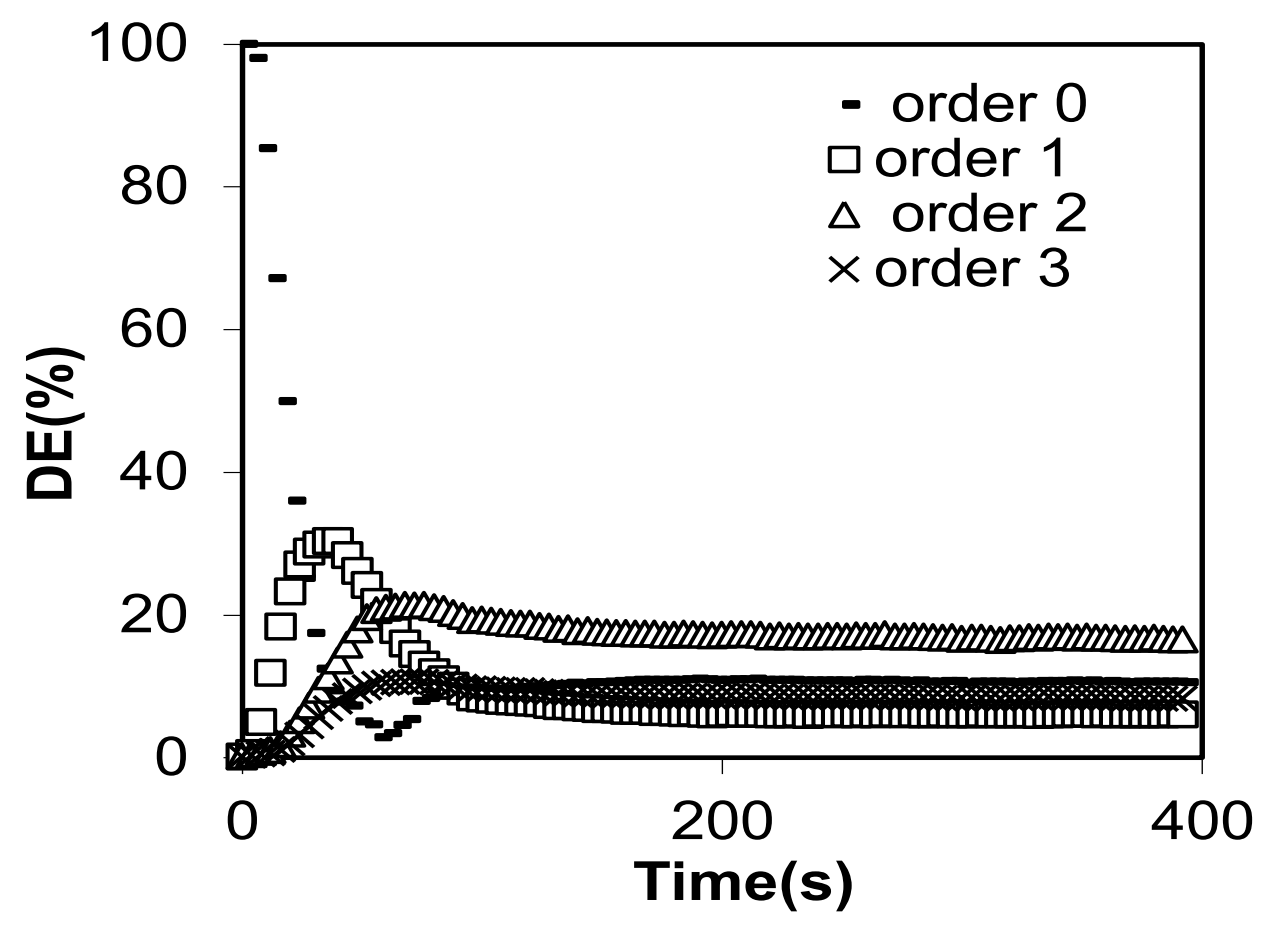


FIGURE 4

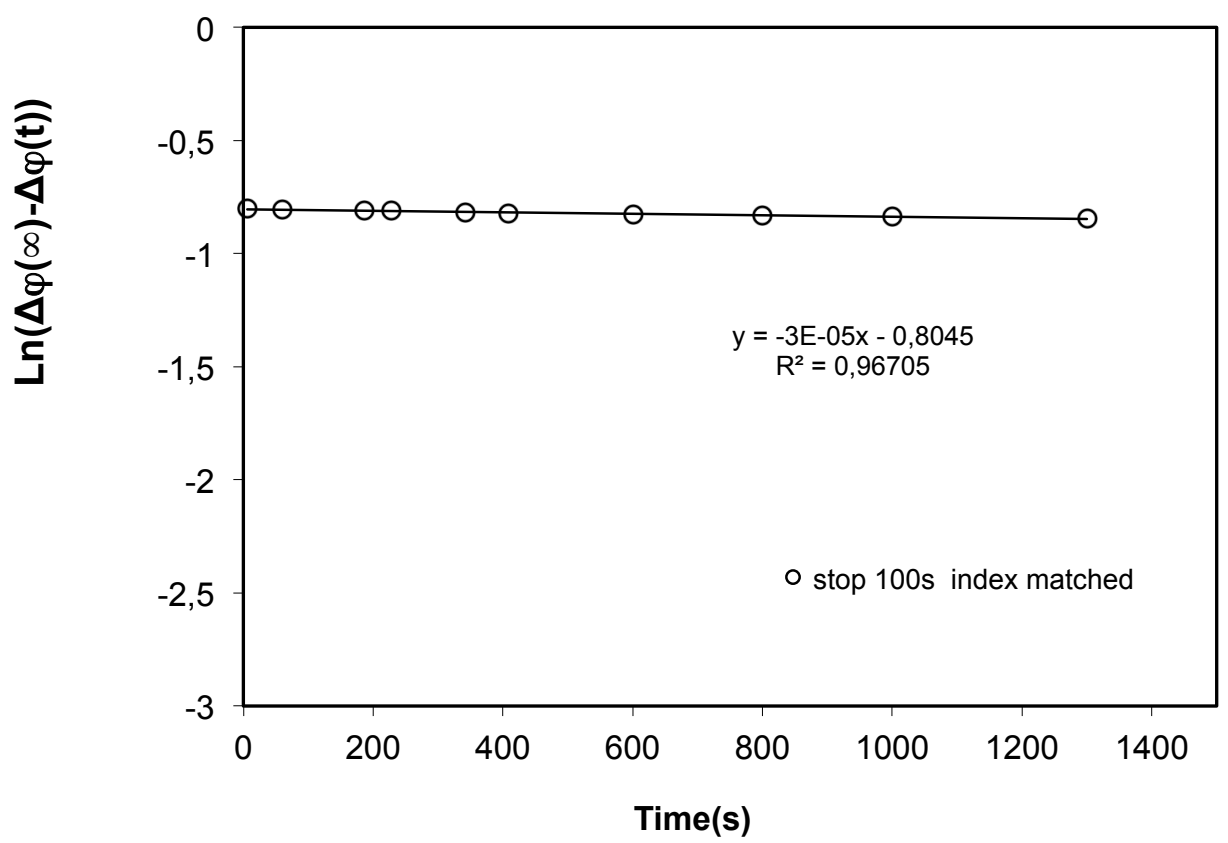


FIGURE 5

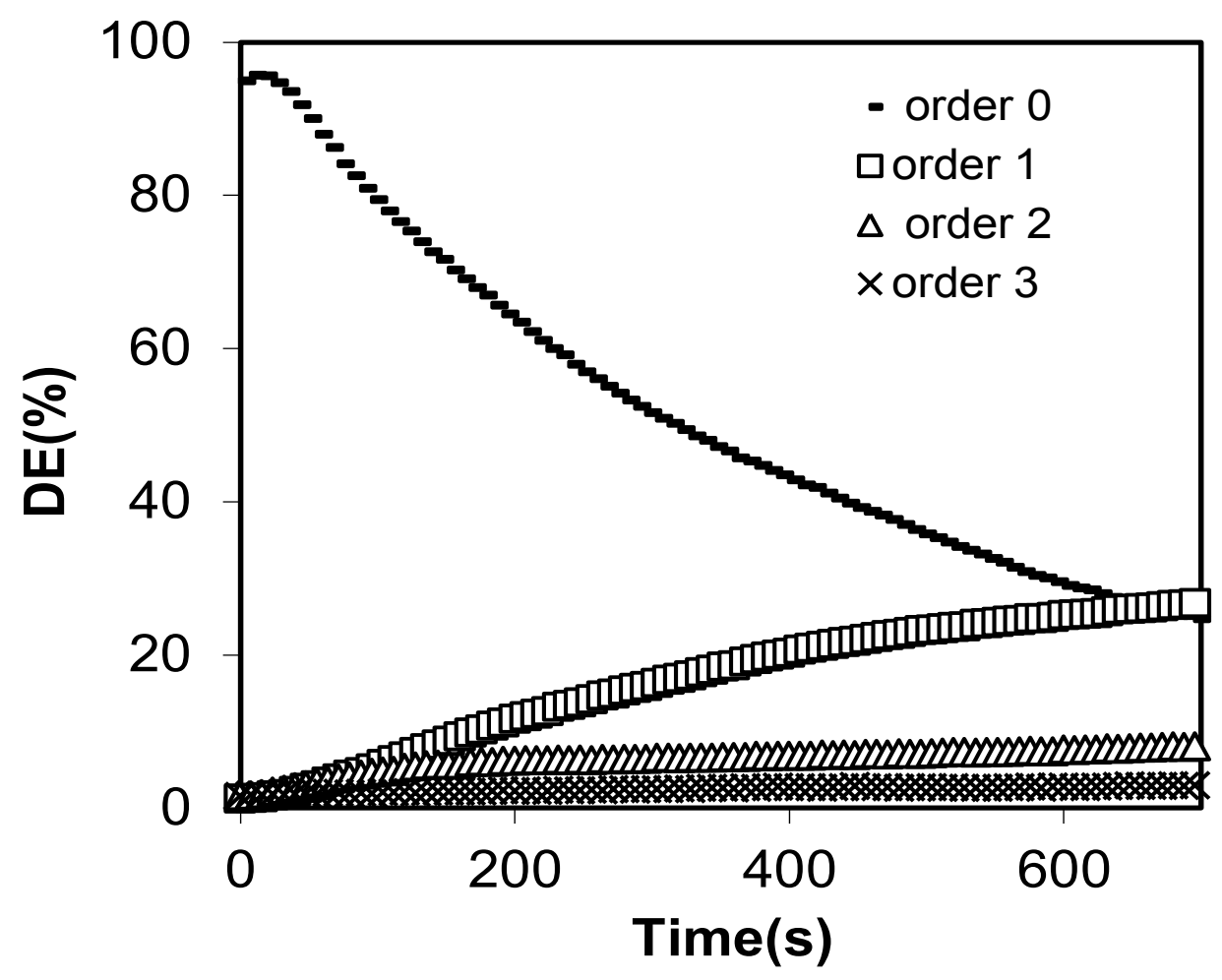


FIGURE 6a

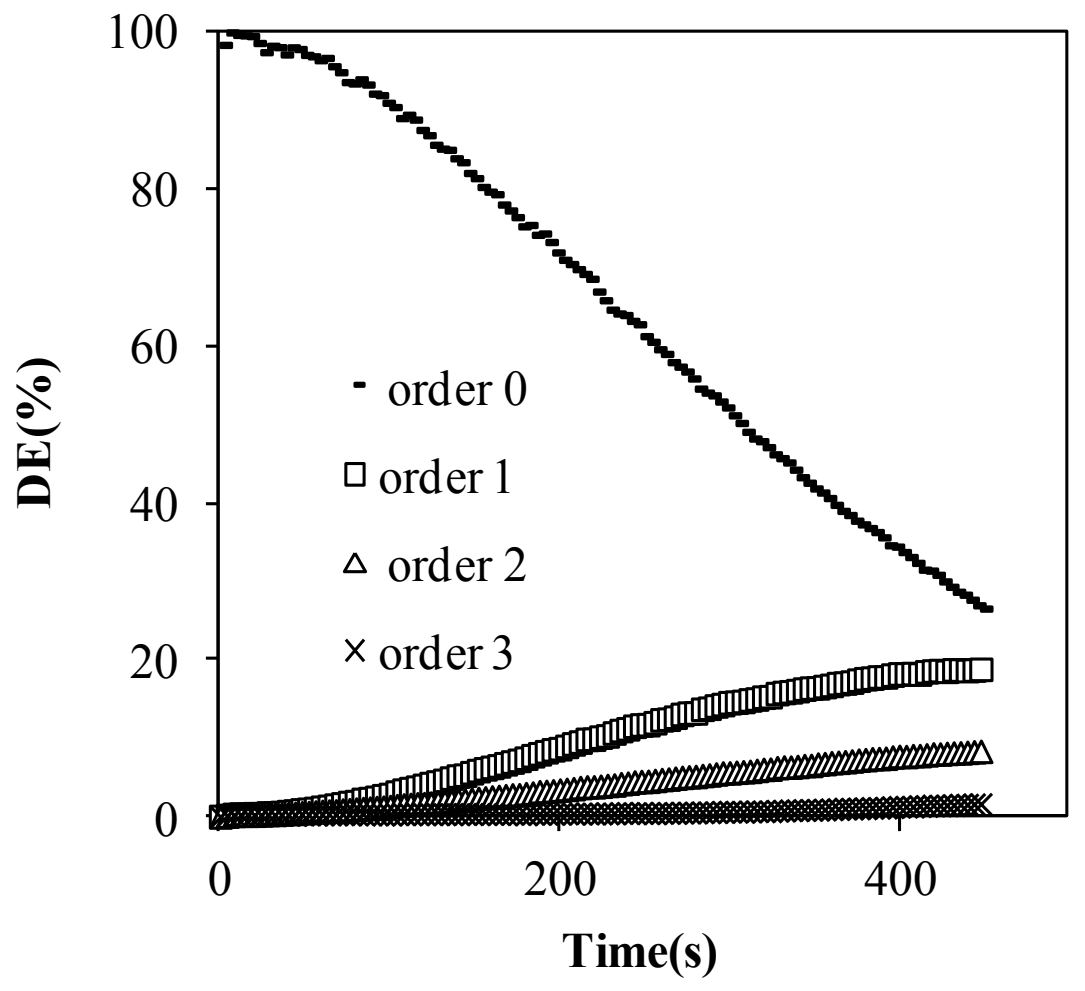


FIGURE 6b

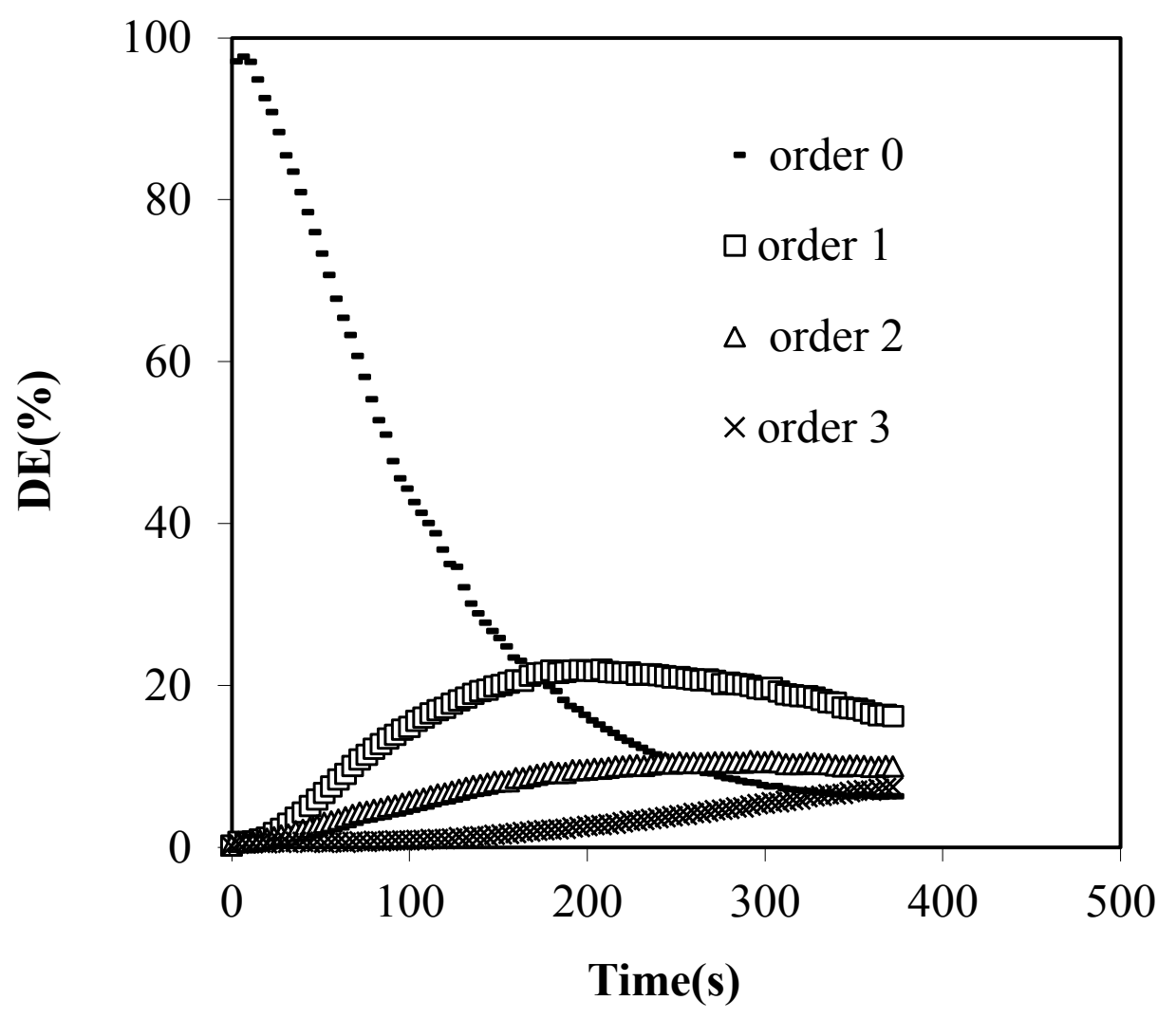


FIGURE 7

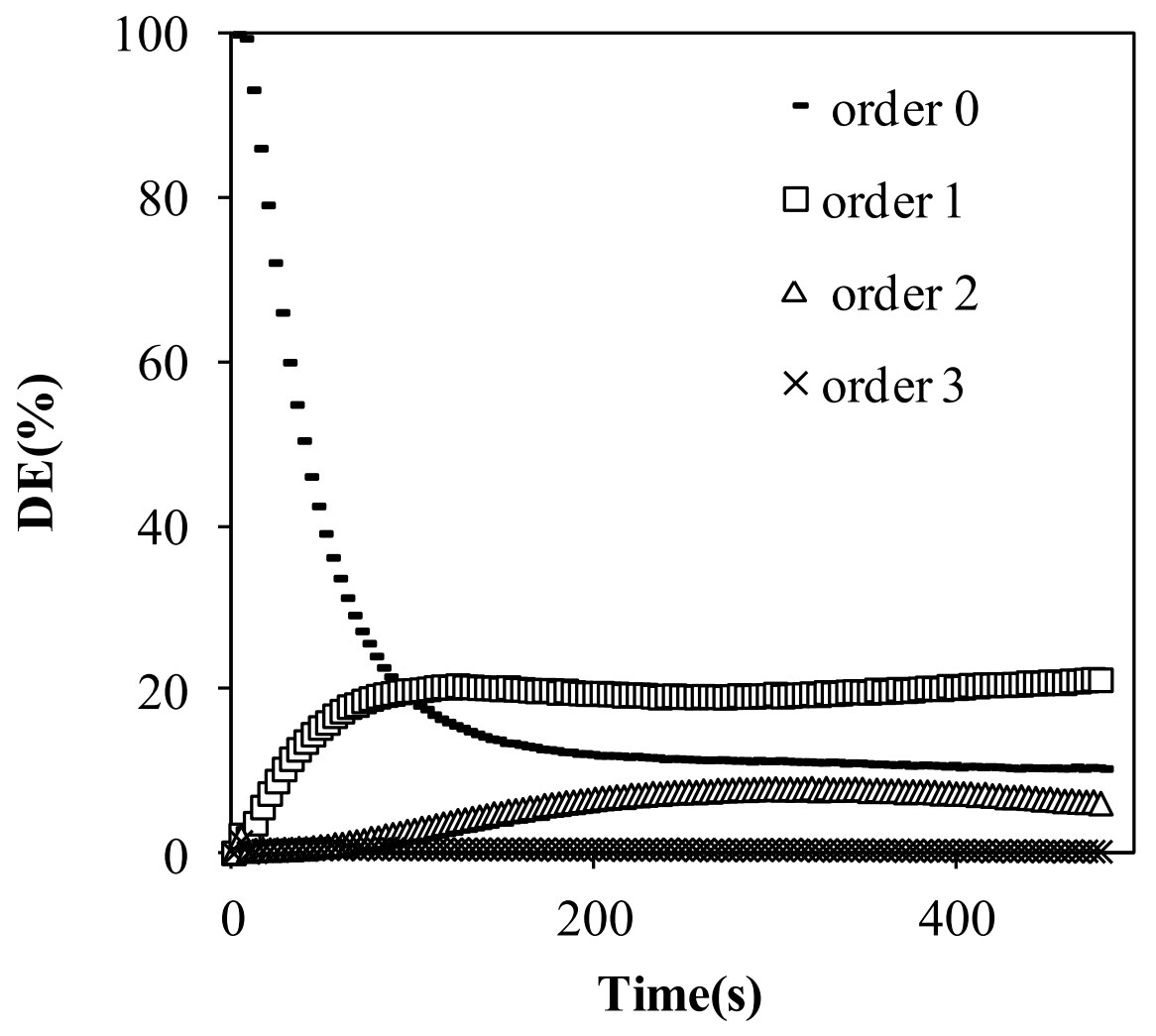


FIGURE 8a

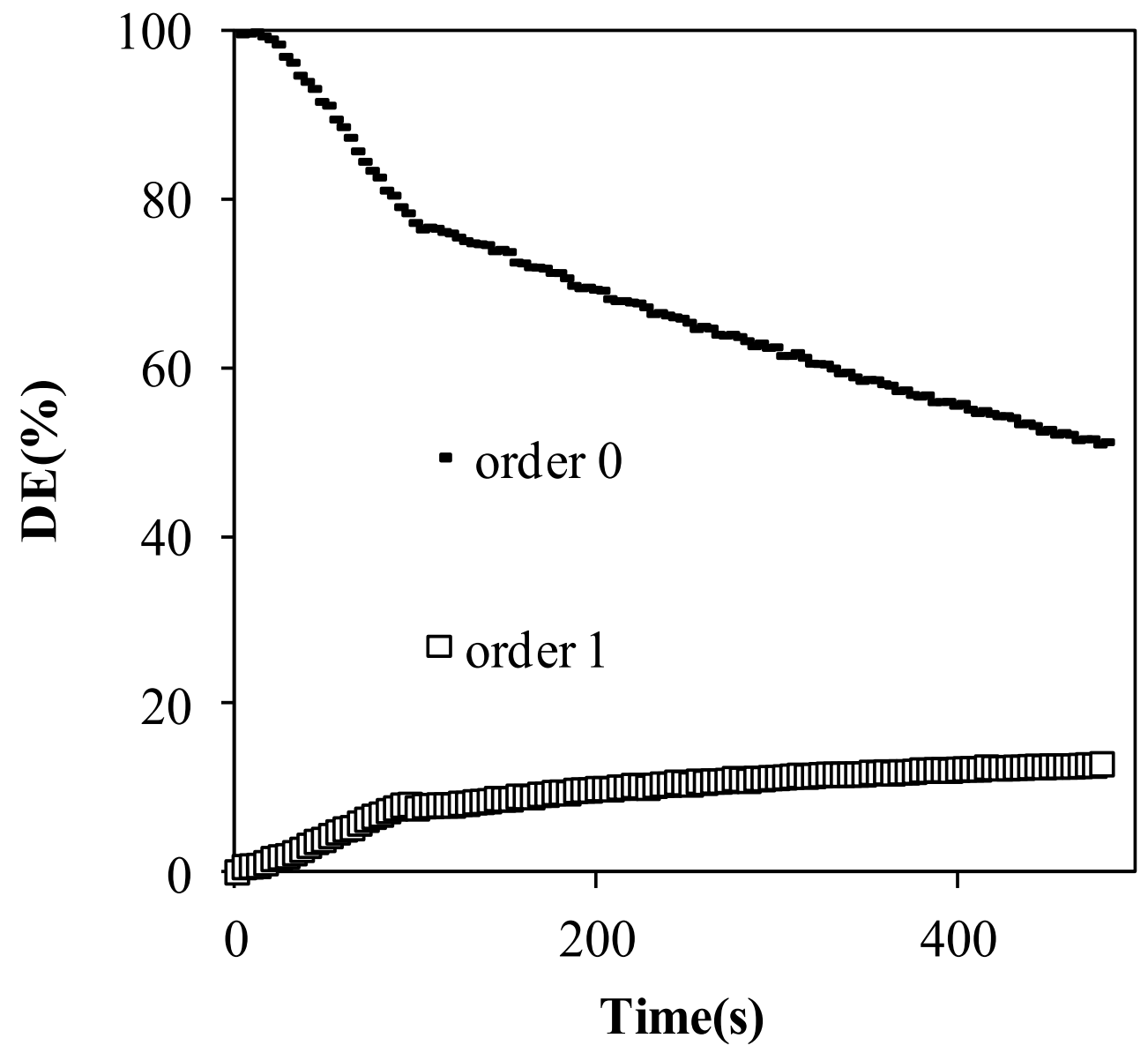


FIGURE 9

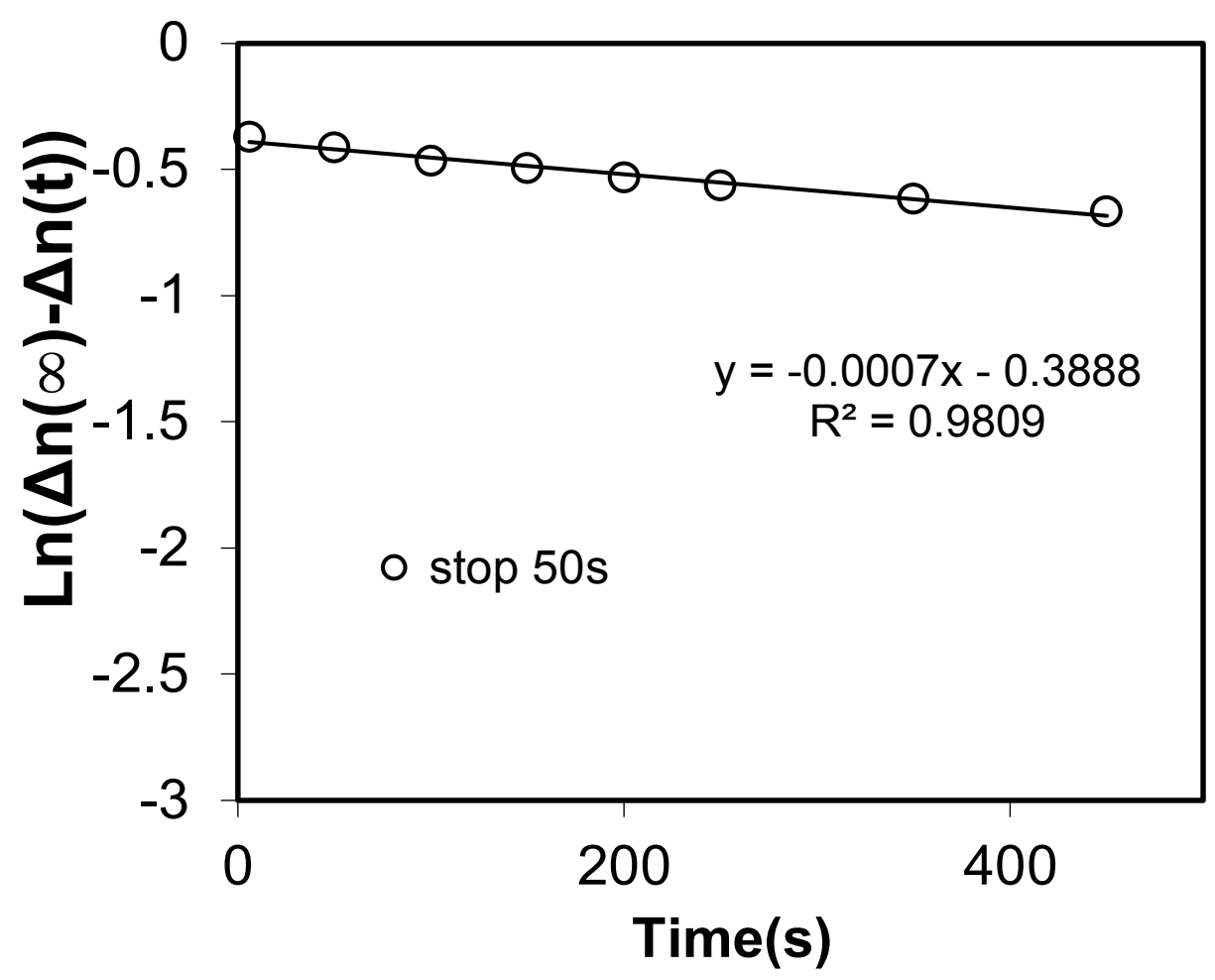


FIGURE 10a

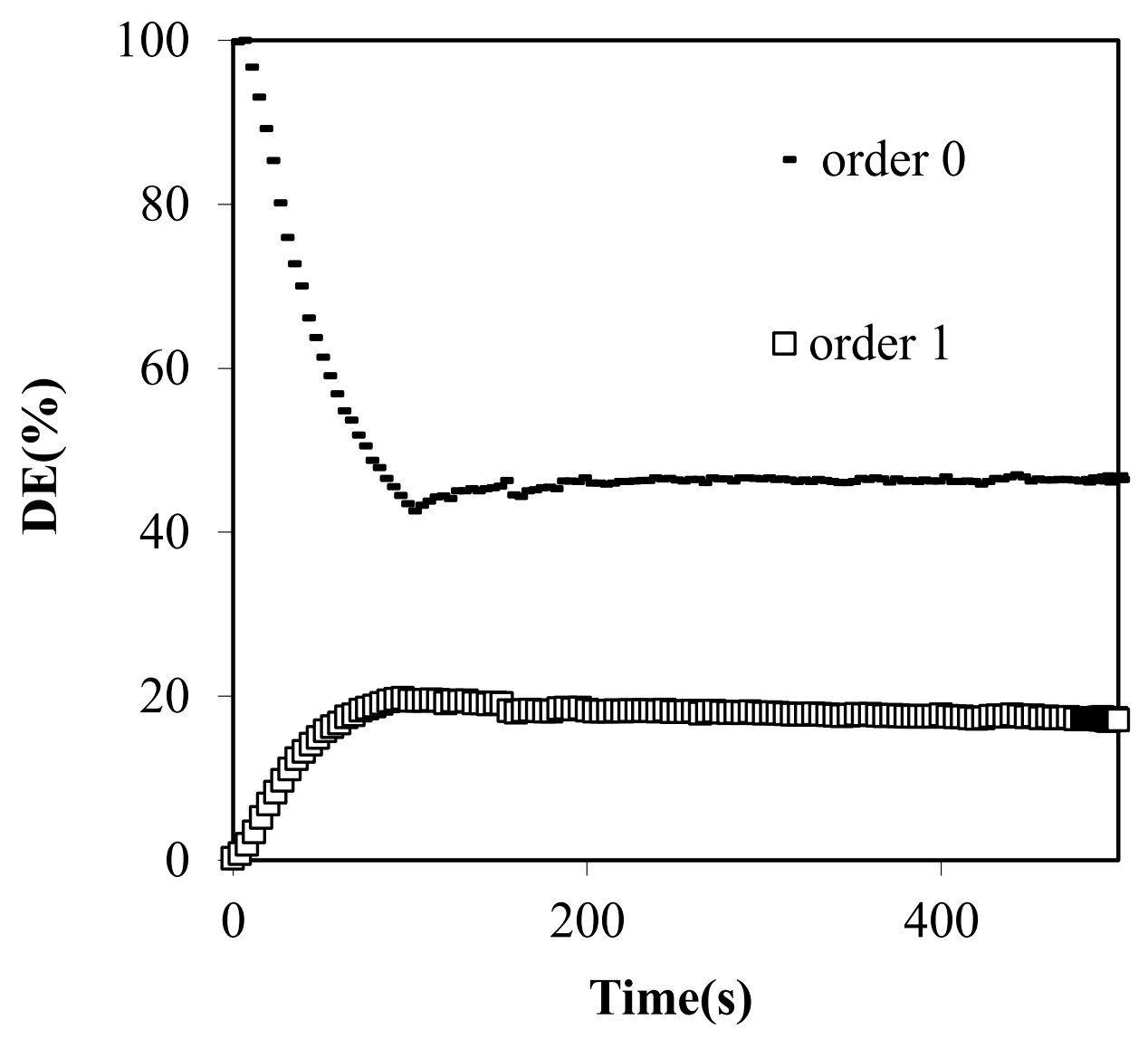


FIGURE 10b

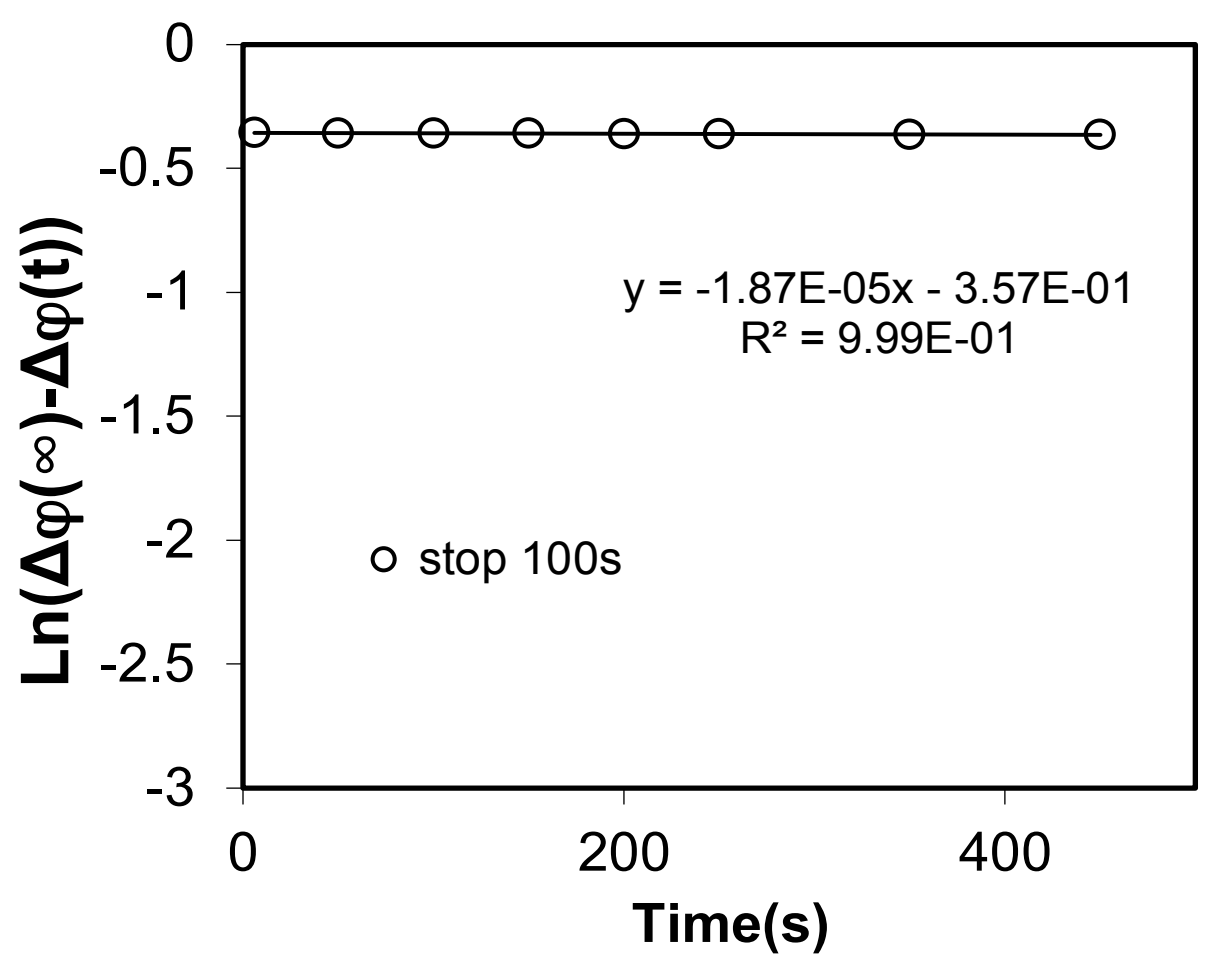


Fgure 11a

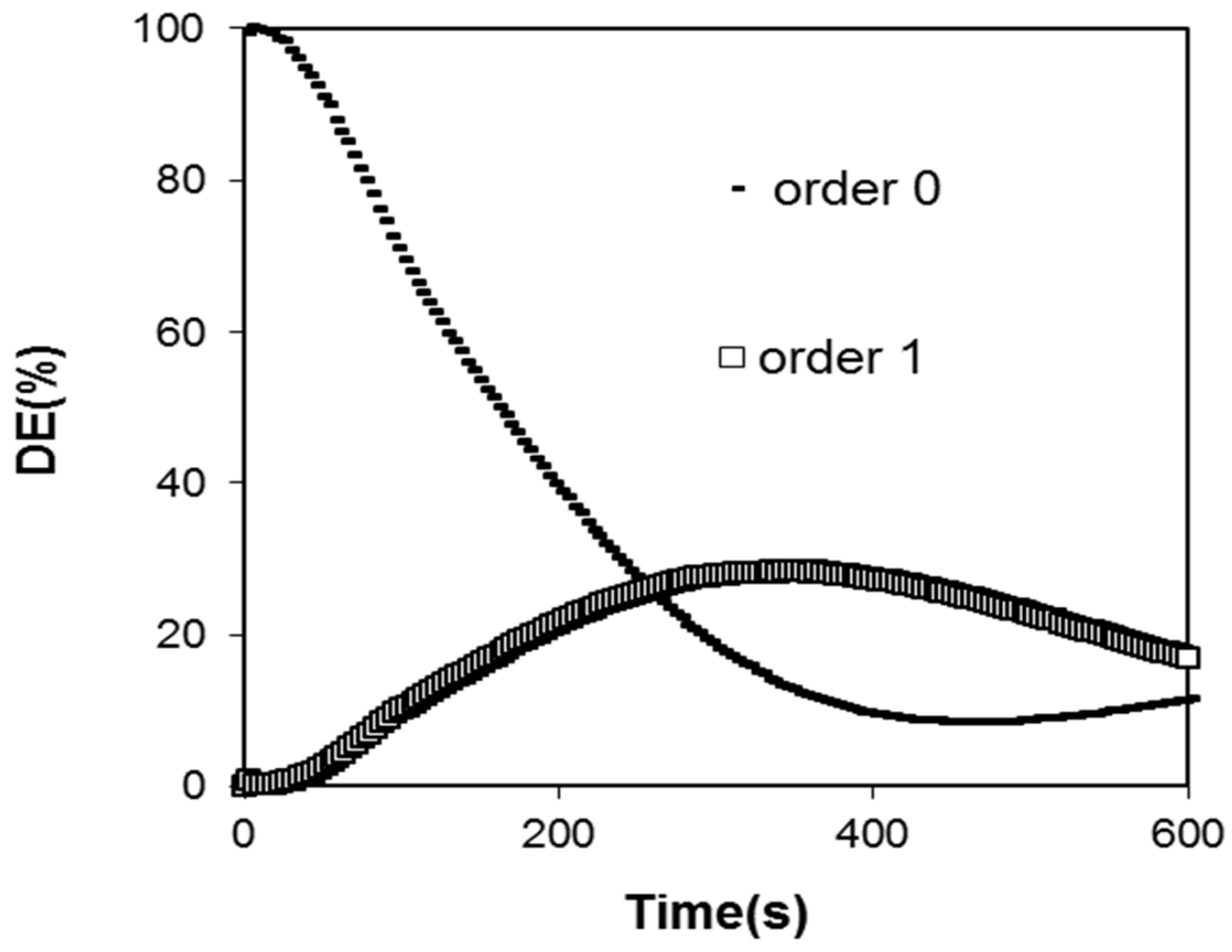


FIGURE 11b

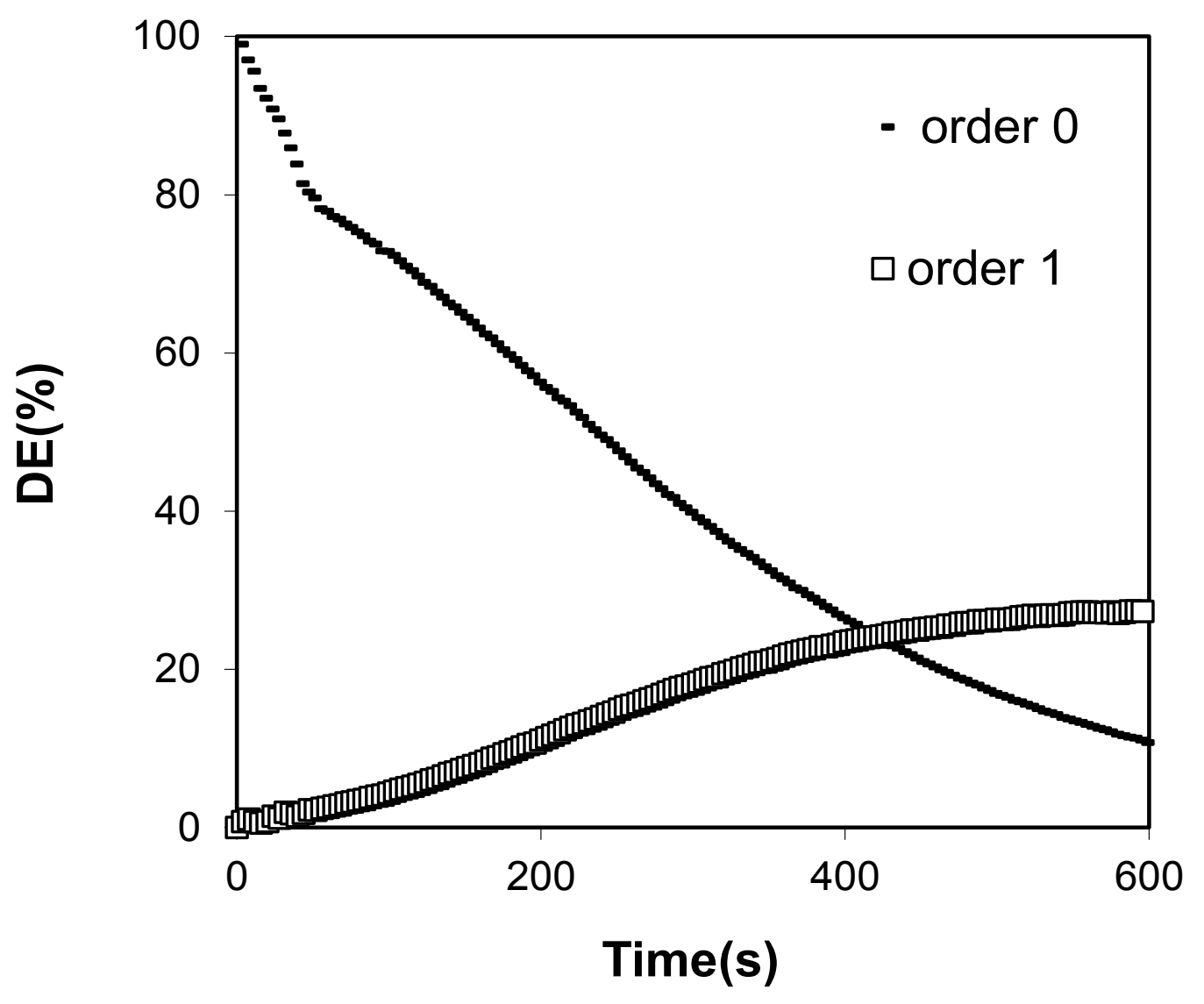


FIGURE 11c

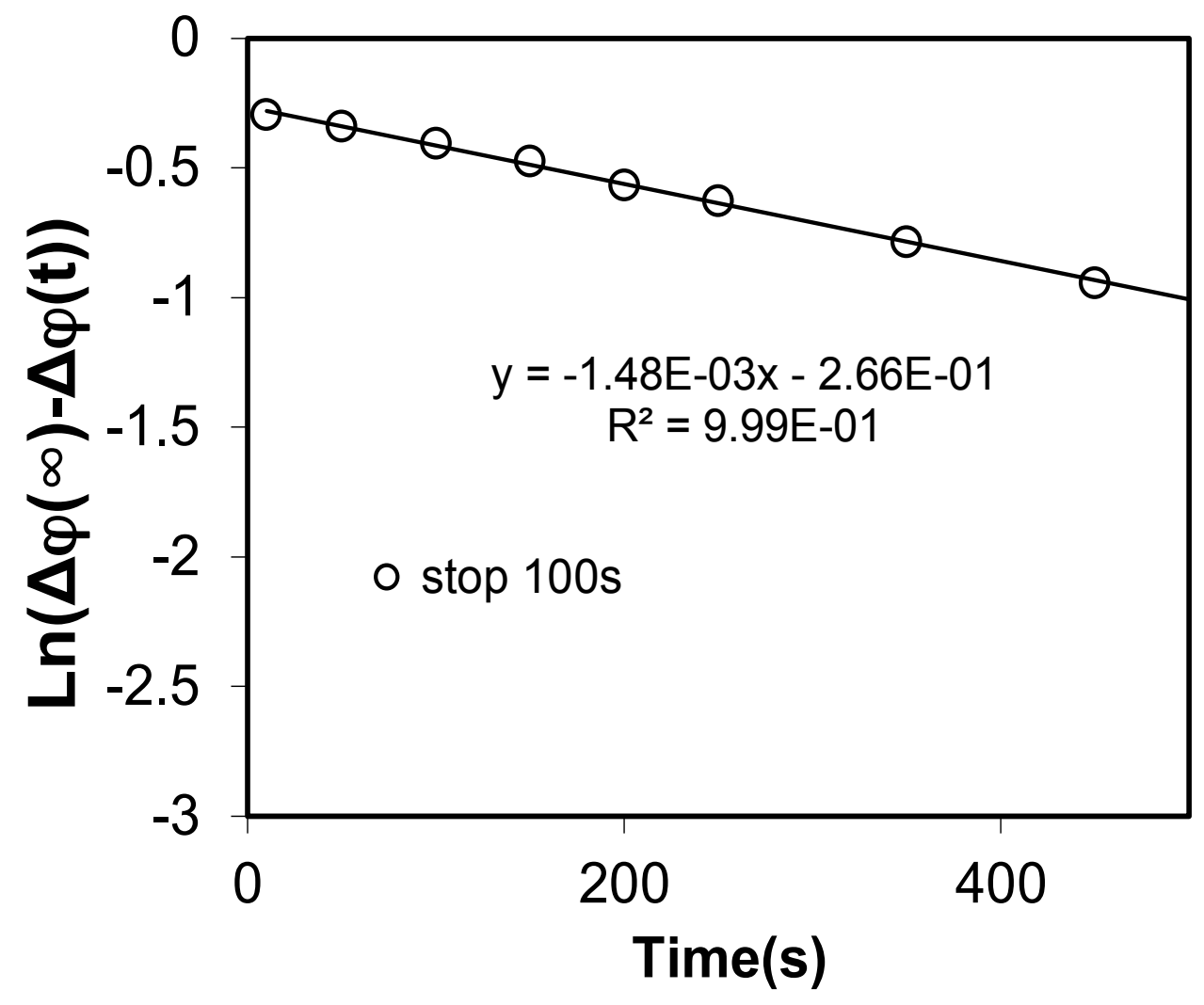

